\title{
Seasonality of Acute Retinal Necrosis
}

\author{
Alireza Hedayatfar ${ }^{1,2}$, MD; Maryam Ashraf Khorasani ${ }^{1}$, MD; Mehdi Behnia ${ }^{2}$, MD; Ahad Sedaghat ${ }^{1}$, MD \\ ${ }^{1}$ Eye Research Center, Rassoul Akram Hospital, Iran University of Medical Sciences, Tehran, Iran \\ ${ }^{2}$ Noor Ophthalmology Research Center, Noor Eye Hospital, Tehran, Iran \\ ORCID: \\ Alireza Hedayatfar: https://orcid.org/0000-0002-5667-5379
}

\section{Abstract}

Purpose: To study the seasonal variability in the occurrence of acute retinal necrosis $(A R N)$ in a series of polymerase chain reaction (PCR)-positive patients.

Methods: Consecutive patients clinically diagnosed with ARN and a positive PCR result of aqueous humor during a seven-year period were studied retrospectively. Patients' demographics, causative viral agent(s), and the date of disease onset were extracted from medical records.

Results: Twenty eyes of 20 patients were enrolled; the mean age at presentation was $39.6 \pm 14.4$ (range, $6-62$ ) years. Nine patients were female. The most common causative agent was varicella-zoster virus in 16 patients (80\%), followed by herpes simplex virus in two patients (10\%). The disease onset was in winter in 10 patients $(50 \%)$, and the highest incidence was in February (five patients, 25\%). The cumulative occurrence of ARN was significantly higher in the first half of the year (winter and spring) compared to the second half of the year (summer and fall) $(P=0.030)$. In general, seasons with a high incidence of ARN were preceded by cold seasons.

Conclusion: In our series, we observed seasonal variability in the incidence of ARN, with the highest incidence during winter and spring. However, further epidemiologic studies in different geographical areas are required to elucidate the true seasonal nature of ARN.

Keywords: Acute Retinal Necrosis; Herpetic Viral Retinitis; Polymerase Chain Reaction; Seasonal Variation; Varicella-Zoster Virus

J Ophthalmic Vis Res 2020; 15 (1): 53-58

\section{Correspondence to:}

Alireza Hedayatfar, MD. Ocular Inflammation and Uveitis Clinic, Noor Eye Hospital, No. 96 Esfandiar Blvd., Vali'asr Ave., Tehran 19686, Iran.

E-mail:alireza.hedayatfar@gmail.com

Received: 03-12-2018Ａccepted: 17-07-2019

\section{Access this article online}

\section{Website:}

https://knepublishing.com/index.php/JOVR

DOI:

10.18502/jovr.v15i1.5944

\section{INTRODUCTION}

Acute retinal necrosis (ARN) was first described in 1971 by Urayama et al as a syndrome of acute panuveitis with retinal periarteritis progressing to diffuse necrotizing retinitis and retinal detachment (RD). ${ }^{[1]}$ This uncommon but potentially blinding

This is an open access journal, and articles are distributed under the terms of the Creative Commons Attribution-NonCommercial-ShareAlike 4.0 License, which allows others to remix, tweak, and build upon the work non-commercially, as long as appropriate credit is given and the new creations are licensed under the identical terms.

How to cite this article: Hedayatfar A, Ashraf Khorasani M, Behnia M Sedaghat A. Seasonality of Acute Retinal Necrosis. J Ophthalmic Vis Res 2020;15:53-58. 
condition is usually noticed in immunocompetent hosts but occasionally among immunocompromised patients. ${ }^{[2,3]}$ In a nationwide survey in the UK, the estimated incidence of ARN was one case per 2 million people per year, which had been stable over one decade. ${ }^{[4,5]}$

ARN is caused by members of the Herpesviridae family, most commonly varicella-zoster virus (VZV) and herpes simplex virus (HSV), and occasionally Epstein-Barr virus (EBV) and cytomegalovirus $(\mathrm{CMV}){ }^{[6-8]}$ Although ARN is essentially a clinical diagnosis, ocular fluid polymerase chain reaction (PCR) testing has been widely used as an aid to the diagnosis and identification of the causative virus. $^{[9-12]}$

ARN is a rapidly destructive disease. Systemic antiviral therapy is the mainstay of treatment. Corticosteroids are usually used along with antiviral agents to reduce the ocular inflammation. Antivirals hasten the remission of retinitis in the affected eye and have a protective effect on the fellow eye. ${ }^{[13]}$ Moreover, early laser retinopexy can reduce the risk of $\mathrm{RD},{ }^{[14,15]}$ which is a complication that is considered a major cause of poor visual outcome in ARN. ${ }^{[16,17]}$ Therefore, early diagnosis and prompt management are important for reducing ocular morbidity, and can potentially save a significant number of eyes from severe vision loss.

In this retrospective chart review, we observed a clustering tendency in the occurrence of ARN in specific months of the year; this observation could highlight important aspects of the epidemiology of the disease.

\section{METHODS}

We retrospectively reviewed the medical records of patients diagnosed with ARN at two referral centers in Tehran from January 2011 to December 2017. Only eyes with positive aqueous PCR were included. The study protocol was approved by the Institutional Review Boards, and informed consent was obtained from the participants at the time of anterior chamber paracentesis. Data on the demographics, causative viral agent(s), and date of the start of the ocular symptoms (considered as disease onset) were extracted. ARN was clinically diagnosed based on the characteristic clinical features consisting of the presence of one or multiple peripheral foci of retinitis with rapid circumferential progression, occlusive retinal vasculitis (mainly arteritis), and prominent vitreous inflammation. Wide-field fluorescein angiography was used to confirm the occlusive nature of vasculitis and extent of retinal ischemia. A tailored laboratory work-up was performed to assess the immune status of the patients and rule-out other causes of uveitis. The average temperatures in each month from January 2011 to December 2017 were extracted based on the data provided by the WorldWeatherOnline.com in Tehran, Mehrabad Airport.

\section{Technique of anterior chamber paracentesis and PCR}

For aqueous sampling, anterior chamber paracentesis was performed using a 30-gauge needle attached to an insulin syringe, and 0.1$0.2 \mathrm{cc}$ of aqueous humor was aspirated. The procedure was generally performed in the clinic after the examination. For patients who received an intravitreal injection of ganciclovir, both sampling and injection were performed in the operating room. The samples were kept at $2-8^{\circ} \mathrm{C}$ and delivered to the laboratory within $1 \mathrm{~h}$ and were stored at $-20^{\circ} \mathrm{C}$. DNA extraction was performed within one week using High Pure Viral Nucleic Acid Kit (Roche Diagnostics $\mathrm{GmbH}$, Mannheim, Germany) following the manufacturer's instructions. ${ }^{[18]}$ Qualitative PCR was performed using the flash method by the DNA Technology Kit (DNA-Technology, Moscow, Russia). ${ }^{[19]}$

The results are expressed as mean \pm standard error. Due to the limited number of cases, Fisher's exact test was used to compare the cumulative occurrence of ARN between the first and second halves of the year. A $p$-value $<0.05$ was considered statistically significant.

\section{RESULTS}

Twenty eyes of 20 patients were included in this study. The mean age at presentation was 39.6 \pm 14.4 (range: $6-62$ ) years. Nine patients were female. None of the patients were HIV-positive. ARN was unilateral in all patients except one [Table 1]. The patient with bilateral ARN did not consent for bilateral sampling, therefore, only the eye with more extensive involvement was sampled (positive 
Table 1. Demographics, causative viral agent(s), and date of disease onset in ARN cases

\begin{tabular}{lcccccc}
\hline Patient \# & PCR result & Gender & Age at onset (years) & Laterality & ARN onset (month) & ARN onset (year) \\
\hline 1 & VZV & M & 41 & OD & 6 & 2013 \\
2 & VZV & M & 30 & OS & 5 & 2014 \\
3 & VZV & $\mathrm{F}$ & 56 & OD & 1 & 2016 \\
4 & VZV & $\mathrm{F}$ & 28 & OS & 4 & 2013 \\
5 & VZV & M & 58 & OD & 10 & 2015 \\
6 & VZV & M & 53 & OS & 2 & 2011 \\
7 & VZV & M & 45 & OD & 5 & 2012 \\
8 & VZV & F & 44 & OU & 8 & 2013 \\
9 & VZV & F & 45 & OD & 6 & 2017 \\
10 & VZV & M & 40 & OD & 1 & 2015 \\
11 & VZV & M & 21 & OS & 2 & 2017 \\
12 & VZV & F & 35 & OS & 2 & 2016 \\
13 & VZV & M & 48 & OS & 1 & 2017 \\
14 & VZV & M & 56 & OS & 3 & 2015 \\
15 & VZV & F & 29 & OD & 3 & 2015 \\
16 & VZV, EBV & F & 62 & OS & 4 & 2016 \\
17 & HSV & M & 6 & OS & 2 & 2017 \\
18 & HSV & M & 25 & OD & 2 & 2014 \\
19 & EBV & F & 26 & OD & 3 & 2017 \\
20 & CMV & M & 43 & OD & 5 & 2014 \\
& & & & &
\end{tabular}

ARN, acute retinal necrosis; CMV, cytomegalovirus; EBV, Epstein-Barr virus; F, female; HSV, Herpes Simplex virus; m, male; OD, right eye; OS, left eye; OU, bilateral; PCR, polymerase chain reaction; VZV, Varicella-Zoster Virus

for VZV) while the other eye was excluded from the study.

Based on the PCR results, the most common causative agent was VZV detected in 16 patients (80\%), followed by HSV in 2 patients (10\%; HSV-1 and HSV-2 each in one patient). CMV was detected in one patient (5\%) and EBV in one eye (5\%). In one VZV-positive patient, a simultaneous co-infection by EBV was present [Table 1].

In most patients (85\%, 17 patients), the disease onset was in winter (ten patients, 50\%) or spring (seven patients, 35\%). Summer (two patients, $10 \%$ ) and autumn (one patient, 5\%) were the seasons with the lowest incidence [Figure 1(a)]. February was the month with the highest incidence of ARN (five patients, 25\%), and July, September, November, and December were the months with the lowest incidence (no cases) [Figure 1(b)]. The cumulative occurrence of ARN was significantly higher in the first half of the year (winter and spring) compared to the second half of the year (summer and fall) $(P=$ 0.030).

Figure 2 shows the average temperature in each month during the study period. The coldest month in the study period was January (mean temperature, $5.1^{\circ} \mathrm{C}$ ), followed by February (mean temperature, $6.5^{\circ} \mathrm{C}$ ) and December (mean temperature, $7.0^{\circ} \mathrm{C}$ ). July (mean temperature, $34.0^{\circ} \mathrm{C}$ ), August (mean temperature, $32.9^{\circ} \mathrm{C}$ ), and June (mean temperature, $31.7^{\circ} \mathrm{C}$ ) were the warmest months. The coldest season that was winter (average temperature, $7.7^{\circ} \mathrm{C}$ ) had the highest incidence of ARN (50\%). Autumn, which was the second coldest season (average temperature, $12.9^{\circ} \mathrm{C}$ ), had the lowest incidence of ARN (5\%). The high incidence rate of ARN (35\%) in spring suggests a time lag between the beginning of cold seasons and an increase in the incidence of ARN. 
Cumulative number (percent) of $\mathrm{ARN}^{*}$ during 7-year-period
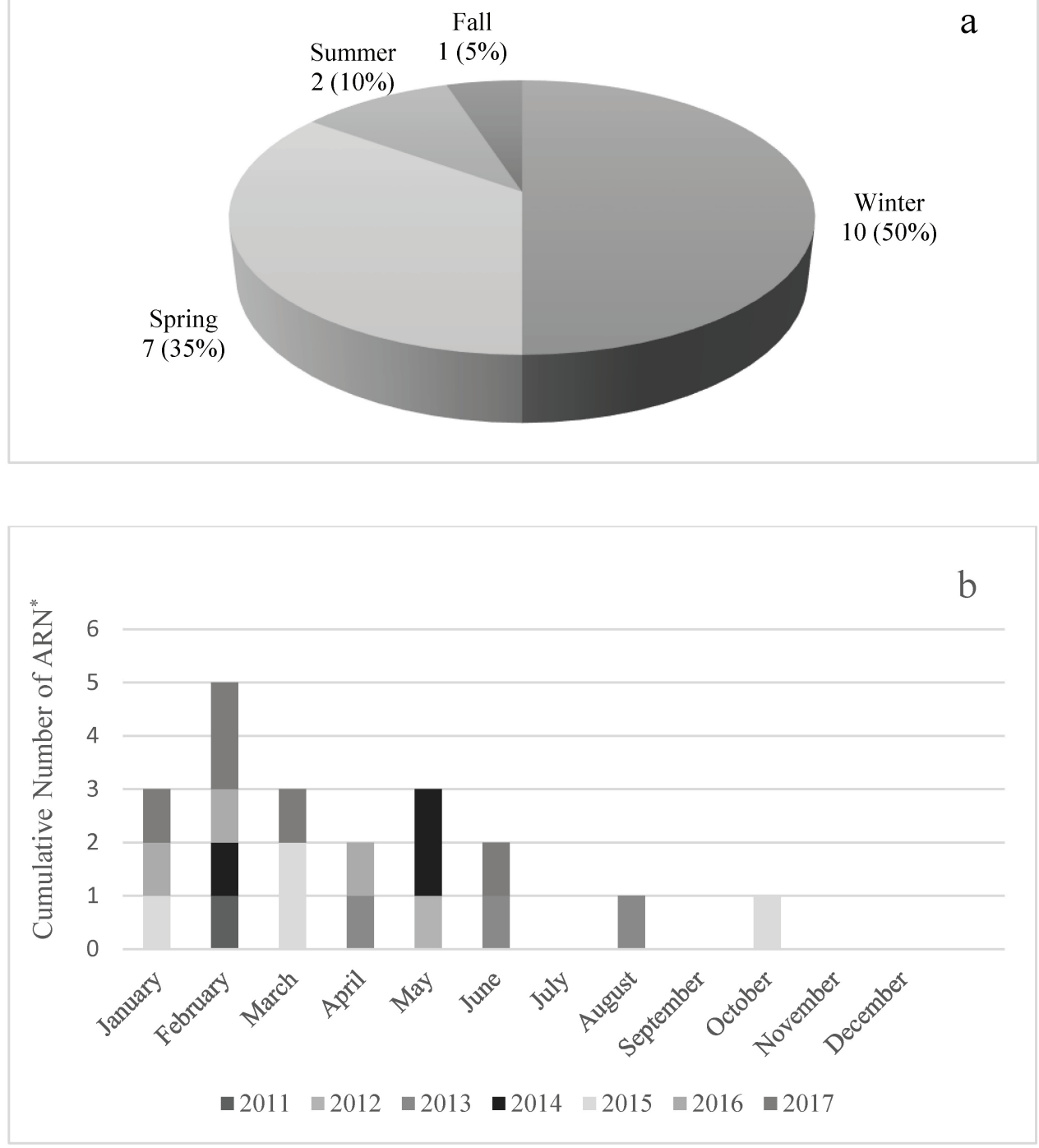

* Acute Retinal Necrosis

Figure 1. Cumulative number of cases of acute retinal necrosis in each season (a) and month (b).

\section{DISCUSSION}

In this series, there was a tendency for the occurrence of ARN during winter and spring. The seasons with a high incidence of ARN were preceded by cold seasons. While the temperature began dropping mid-autumn, the peak of ARN occurred during winter, and once the temperature started rising mid-spring, the incidence of ARN declined in summer.

Previous studies have shown patterns of seasonal variability in the incidence of infections associated with the Herpesviridae family. Varicella shows pronounced seasonality in temperate climates and most tropical climates, with a peak incidence in the cooler, drier months during winter or spring. ${ }^{[20-23]}$ In a study using the Connecticut statewide hospital discharge database in the prevaccine era, $73.2 \%$ of the varicella hospitalizations occurred during winter and spring. ${ }^{[24]}$ In contrast, zoster does not show any seasonal pattern in the UK, Canada, ${ }^{[25]}$ or Western Australia. ${ }^{[26]}$ Seasonal variations in the occurrence of herpetic keratitis were reported as well. In a study in Japan, a negative correlation was observed between the incidence of dendritic keratitis recurrences 


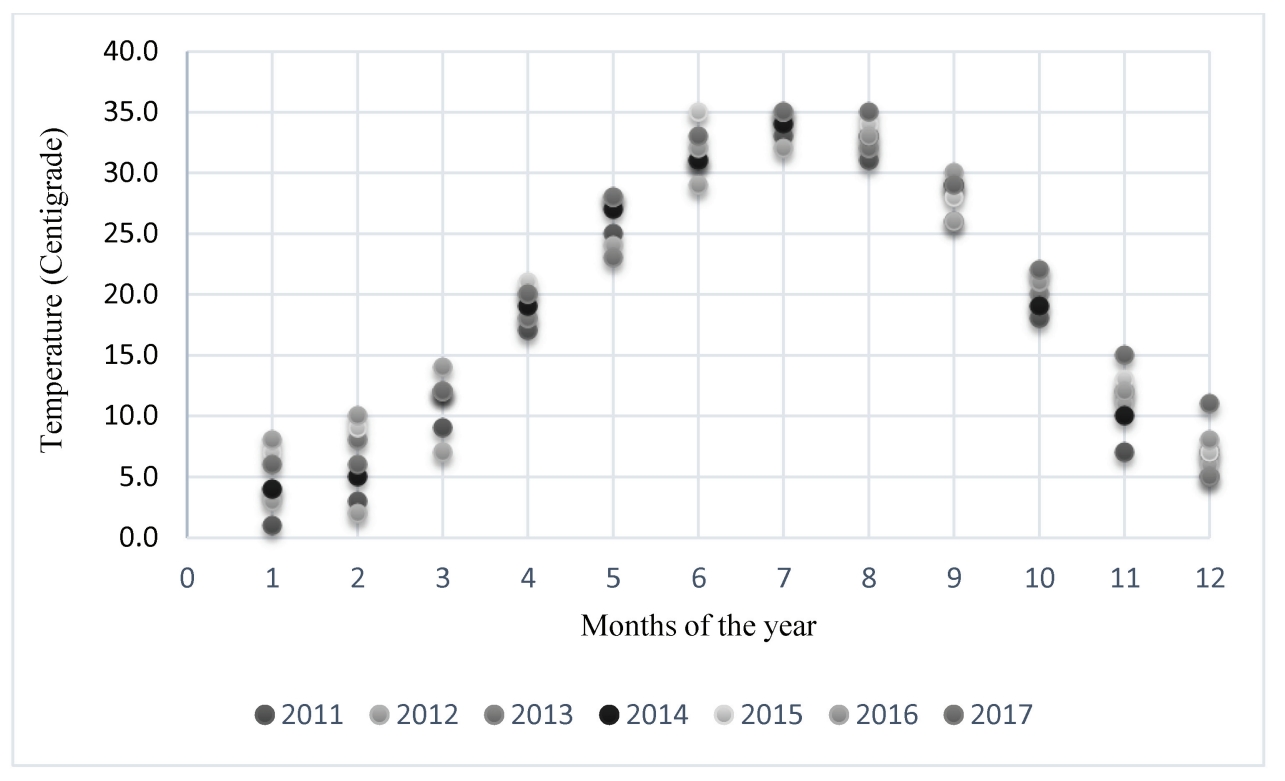

Figure 2. Average temperature in each month in the study period.

and temperature and $42.2 \%$ of the recurrences occurred during winter. ${ }^{[27]}$ Gamus found the highest rate of herpetic eye attacks during January, ${ }^{[28]}$ and others reported the highest incidence of herpetic keratitis in late autumn and winter. ${ }^{[29]}$

Seasonal cycles in infectious diseases are generally attributed to seasonal differences in weather conditions, seasonal rhythmicity in host susceptibility to infectious agents, and the virulence or prevalence of causal pathogens. ${ }^{[30,31]}$ The explanation of the seasonal variability in the incidence of ARN in this series would be undoubtedly complex and multifactorial. Tehran has a four-season climate. The weather is usually mild and rainy in spring, hot and dry in summer, mild to cold in autumn, but chilly and occasionally snowy in winters. Records of the average monthly temperature also showed that winter and autumn were the coldest seasons. The higher incidence rate of ARN in winter and spring suggests a temporal pattern in which the cold seasons preceded seasons with a high incidence of ARN. However, this is an assumption and cannot be confirmed using statistical methods. Administering the time series analysis, which is often used to extract possible correlations in similar situations, needs a large sample size far exceeding the number of cases included in the current study.

To the best of our knowledge, this is the first report on the concept of seasonality in ARN. We included a homogenous group of patients with PCR-proven ARN and set Tehran, a four-season city, as the reference to evaluate the probable climatological association. A limitation of the current study is the small sample size, which is due to the rarity of ARN. The second limitation is that the temperature data were collected based on records provided from a single station in Tehran (Mehrabad Airport). Considering the area of the Tehran metropolitan, a single station may not comprehensively reflect the whole climate of the source population.

The knowledge of the seasonal variability in the incidence of ARN could potentially be beneficial to ophthalmologists to expect new cases during specific months of the year and be prompt in diagnosis and treatment. However, further epidemiologic studies in different geographical areas are required to elucidate the true seasonal nature of ARN.

\section{Financial Support and Sponsorship}

Nil.

\section{Conflicts of Interest}

There are no conflicts of interest. 


\section{REFERENCES}

1. Urayama A, Yamada N, Sasaki T. Unilateral acute uveitis with periarteritis and detachment. J Clin Ophthalmol 1971;25:607-619.

2. Freeman WR, Lerner CW, Mines JA, Lash RS, Nadel AJ, Starr MB, et al. A prospective study of the ophthalmologic findings in the acquired immune deficiency syndrome. Am J Ophthalmol 1984;97:133-142.

3. Bonfioli AA, Eller AW. Acute retinal necrosis. Semin Ophthalmol 2005;20:155-160.

4. Muthiah MN, Michaelides M, Child CS, Mitchell SM. Acute retinal necrosis: a national population-based study to assess the incidence, methods of diagnosis, treatment strategies and outcomes in the UK. Br J Ophthalmol 2007;91:1452-1455.

5. Cochrane TF, Silvestri G, McDowell C, Foot B, McAvoy CE. Acute retinal necrosis in the United Kingdom: results of a prospective surveillance study. Eye 2012;26:370-377.

6. Culbertson WW, Blumenkranz MS, Haines H, Gass DM, Mitchell KB, Norton EW. The acute retinal necrosis syndrome. Part 2: histopathology and etiology. Ophthalmo/ogy 1982;89:1317-1325.

7. Matsuo T, Nakayama T, Koyama T, Matsuo N. Cytological and immunological study of the aqueous humor in acute retinal necrosis syndrome. Ophthalmologica 1987;195:3844.

8. Ganatra JB, Chandler D, Santos C, Kuppermann B, Margolis TP. Viral causes of the acute retinal necrosis syndrome. Am J Ophthalmol 2000;129:166-172.

9. Nishi M, Hanashiro R, Mori S, Masuda K, Mochizuki M, Hondo R. Polymerase chain reaction for the detection of the varicella-zoster genome in ocular samples from patients with acute retinal necrosis. Am J Ophthalmol 1992;114:603-609.

10. de Boer $\mathrm{JH}$, Verhagen $\mathrm{C}$, Bruinenberg $\mathrm{M}$, Rothova $\mathrm{A}$, de Jong PT, Baarsma GS, et al. Serologic and polymerase chain reaction analysis of intraocular fluids in the diagnosis of infectious uveitis. Am J Ophthalmol 1996;121:650-658.

11. Gargiulo F, De Francesco MA, Nascimbeni G, Turano R, Perandin F, Gandolfo E, et al. Polymerase chain reaction as a rapid diagnostic tool for therapy of acute retinal necrosis syndrome. J Med Virol 2003;69:397-400.

12. Tran TH, Rozenberg F, Cassoux N, Rao NA, LeHoang P, Bodaghi B. Polymerase chain reaction analysis of aqueous humour samples in necrotising retinitis. $\mathrm{Br} J$ Ophthalmol 2003;87:79-83.

13. Palay DA, Sternberg P, Jr, Davis J, Lewis H, Holland GN, Mieler WF, et al. Decrease in the risk of bilateral acute retinal necrosis by acyclovir therapy. Am J Ophthalmol 1991;112:250-255.

14. Han DP, Lewis $\mathrm{H}$, Williams GA, Mieler WF, Abrams GW, Aaberg TM. Laser photocoagulation in the acute retinal necrosis syndrome. Arch Ophthalmol 1987;105:1051-1054.

15. Lau CH, Missotten T, Salzmann J, Lightman SL. Acute retinal necrosis features, management, and outcomes. Ophthalmology 2007;114:756-762.
16. Sims JL, Yeoh J, Stawell RJ. Acute retinal necrosis: a case series with clinical features and treatment outcomes. Clin Exp Ophthalmol 2009;37:473-477.

17. Butler NJ, Moradi A, Salek SS, Burkholder BM, Leung TG, Dunn JP, et al. Acute retinal necrosis: presenting characteristics and clinical outcomes in a cohort of polymerase chain reaction-positive patients. Am J Ophthalmol 2017;179:179-189.

18. Roche Diagnostics $\mathrm{GmbH}$, Germany. High Pure Viral Nucleic Acid Kit. Version: 19. 2015; August. Cat. No. 11858 874 001. Available from: https://lifescience.roche.com

19. “DNA-Technology” Multicorporate Enterprise, Russia. Catalogue Equipment. Last version. Available from: http:// www.dna-technology.ru

20. Deguen S, Chau NP, Flahault A. Epidemiology of chickenpox in France (1991-1995). J Epidemiol Community Health 1998;52:46S-49S.

21. Lee BW. Review of varicella zoster seroepidemiology in India and Southeast Asia. Trop Med Int Health 1998;3:886-890.

22. Tobias M, Reid S, Lennon D, Meech R, Teele DW. Chickenpox immunization in New Zealand. N Z Med J 1998;111:274281.

23. Bramley JC, Jones IG. Epidemiology of chickenpox in Scotland: 1981 to 1998. Commun Dis Public Health 2000;3:282-287.

24. Lin F, Hadler JL. Epidemiology of primary varicella and herpes zoster hospitalizations: the pre-varicella vaccine era. J Infect Dis 2000;181:1897-905.

25. Brisson M, Edmunds WJ, Law B, Gay NJ, Walld R, Brownell $M$, et al. Epidemiology of varicella zoster virus infection in Canada and the United Kingdom. Epidemiol Infect 2001;127:305-314.

26. Korostil IA, Regan DG. Varicella-zoster virus in Perth, Western Australia: seasonality and reactivation. PLOS ONE 2016;10:11.

27. Araki H, Takamura E, Shinozaki K, Hori S. Influence of seasonal variation and recurrence of herpes simplex virus keratitis. Invest Ophthalmol Vis Sci 2004;45:1648.

28. Gamus D, Romano A, Sucher E, Ashkenazi IE. Herpetic eye attacks: variability of circannual rhythms. Br J Ophthalmol 1995;79:50-53.

29. Bell DM, Holman RC, Pavan-Langston D. Herpes simplex keratitis: epidemiologic aspects. Ann Ophthalmol 1982;14:421-422, 424.

30. Dowell, SF. Seasonal variation in host-susceptibility and cycles of certain infectious diseases. Emerg Infect Dis 2001;7:369-374.

31. Shah AP, Smolensky MH, Burau KD, Cech IM, Lai D. Seasonality of primarily childhood and young adult infectious diseases in the United States. Chronobiol Int 2006;23:1065-1082. 